\section{A formação profissional e a consolidação do sistema de saúde}

HADDAD, Ana Estela (Org.). A trajetória dos cursos de graduação na saúde: 1991 a 2004. Brasília: Instituto Nacional de Estudos e Pesquisas Educacionais Anísio Teixeira, 2006. 15 v. em 1 CD.

A primeira iniciativa do governo brasileiro de estabelecer uma política articulada de educação na saúde, por meio de cooperação técnica entre o Ministério da Saúde (MS) e o Ministério da Educação (MEC), está traduzida neste estudo apresentado em 15 volumes. Instituída pela Portaria Interministerial $\mathrm{n}^{0} 2.118$, de 3 de novembro de 2005, tal parceira tem como objetivo reforçar o amplo movimento nacional e internacional que vem destacando a fundamental importância da formação dos profissionais da área para a qualidade do atendimento e a consolidação do sistema de saúde. Este valor é agregado ao investimento em infra-estrutura e tecnologia, recurso adotado por várias décadas como a única medida de desenvolvimento da atenção ao setor.

A trajetória dos cursos de graduação na saúde-1991-2004 é o resultado desse trabalho conjunto organizado pelo Instituto Nacional de Estudos e Pesquisas Educacionais Anísio Teixeira (Inep), autarquia do MEC, e pela Secretaria de Gestão do Trabalho e da Educação na Saúde (SGTES), do MS, no intuito de produzir, aplicar e disseminar conhecimentos a respeito da formação de recursos humanos na saúde brasileira.

Delimitado às 14 categorias profissionais de saúde relacionadas na Resolução $n^{0} 287$ do Conselho Nacional de Saúde, de 8 de outubro de 1998, a metodologia de trabalho deste estudo priorizou a abordagem quantitativa e qualitativa dos cursos de graduação em Biomedicina, Ciências Biológicas, Educação Física, Enfermagem, Farmácia, Fisioterapia, Fonoaudiologia, Medicina, Medicina Veterinária, Nutrição,
Odontologia, Psicologia, Serviço Social e Terapia Ocupacional.

Entre outros referenciais, este estudo parte dos princípios de universalidade, eqüidade, integralidade, descentralização e participação previstos no Sistema Único de Saúde (SUS), além das premissas da Lei de Diretrizes e Bases da Educação Nacional (LDB) e demais legislações vigentes a respeito da saúde no Brasil. Trata, ainda, da qualidade, relevância e adequação da formação em nível superior às necessidades de desenvolvimento do País, parâmetros essenciais para a avaliação dos cursos de graduação, estabelecidos pela Lei do Sistema Nacional de Avaliação da Educação Superior (Sinaes). Deste sistema utilizam, ainda, fontes e dados do Inep a respeito desta etapa do ensino no País.

Assim, preservadas as respectivas responsabilidades e identidades, a presente articulação entre esses dois ministérios busca, através da informação, contribuir com a qualificação da formação acadêmica com vista à melhoria do serviço de saúde prestado à população. Estimula, ainda, a promoção de conhecimentos referentes ao SUS, dirigida aos estudantes como forma de garantir o compromisso dos futuros profissionais com a realidade da saúde do País em todas as suas regiões.

Este levantamento reforça, portanto, o princípio de que a formação deve considerar a realidade social, política e cultural da população. Deste modo, destaca a educação e a saúde como elementos essenciais à coesão da sociedade e à criação de condições dignas de vida.

Maisa Cardoso Consultora - Inep

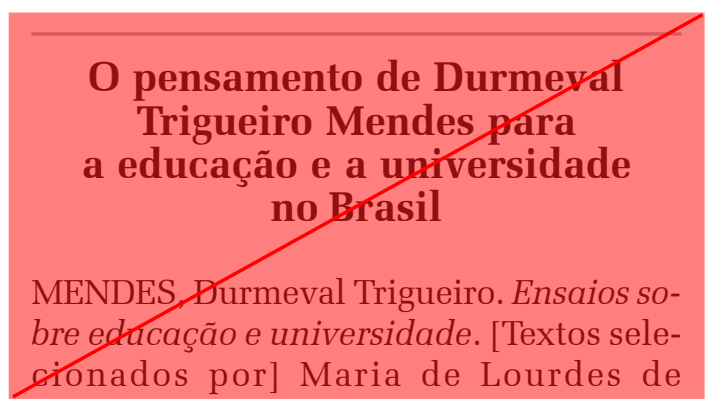

